\title{
Paying for Cures: How Can We Afford It? Managed Care Pharmacy Stakeholder Perceptions of Policy Options to Address Affordability of Prescription Drugs
}

\author{
Kai Yeung, PharmD, PhD; Kangho Suh, PharmD, MS; Anirban Basu, PhD; \\ Louis P. Garrison, PhD; Aasthaa Bansal, PhD; and Josh J. Carlson, PhD, MPH
}

\begin{abstract}
BACKGROUND: High-priced medications with curative potential, such as the newer hepatitis $\mathrm{C}$ therapies, have contributed to the recent growth in pharmaceutical expenditure. Despite the obvious benefits, health care decision makers are just beginning to grapple with questions of how to value and pay for curative therapies that may feature large upfront cost, followed by health benefits that are reaped over a patient's lifespan. Alternative policy options have been proposed to promote high value and financially sustainable use of these therapies. It is unclear which policy options would be most acceptable to health care payer and biomedical manufacturer stakeholders.
\end{abstract}

OBJECTIVES: To (a) briefly review pharmaceutical policy options to address health system affordability and (b) assess the acceptability of alternative policy options to health care payers and biomedical manufacturers before and after an Academy of Managed Care Pharmacy (AMCP) continuing pharmacy education (CPE) session.

METHODS: We searched MEDLINE and Cochran databases for pharmaceutical policy options addressing affordability. With input from a focus group of managed care professionals, we developed CPE session content and an 8-question survey focusing on the most promising policy options. We fielded the survey before and after the CPE session, which occurred as part of the 2016 AMCP Annual Meeting. We first conducted a chi-squared goodness-of-fit test to assess response distributions. Next, we tested how responses differed before and after by using an ordered logit and a multinomial logit to model Likert scale and unordered responses, respectively.

RESULTS: Although risk-sharing payments over time remained the most favorable choice before ( $37 \%)$ and after (35\%) the CPE session, this choice was closely followed by HealthCoin after the session, which increased in favorability from $4 \%$ to $33 \%$ of responses $(P=0.001)$. About half of the respondents $(54 \%)$ indicated that legislative change is the most significant barrier to the implementation of any policy.

CONCLUSIONS: As high-cost curative drugs reach the market, managed care stakeholders need information from a balanced education source regarding alternative policies to address affordability. We found that after the AMCP CPE session, risk-sharing payments over time and HealthCoin were the most favorable options.

J Manag Care Spec Pharm. 2017;23(10):1084-90

Copyright $\odot 2017$, Academy of Managed Care Pharmacy. All rights reserved.

\section{What is already known about this subject}

High-priced specialty medications with curative potential are expected to increasingly affect pharmaceutical expenditures. Traditional utilization management tools, such as prior authorization and step therapy, as currently practiced would not achieve the greatest societal value for cures that are of high value for a large population and for which the value is realized over a patient's lifespan.

Alternative policy options have been proposed, but it is unclear which may be most acceptable to managed care stakeholders.

\section{What this study adds}

This study presents a framework for categorizing the policy options according to their effects on demand, supply, price, or budget. The survey respondents, who attended a continuing pharmacy education session, suggested that risk-sharing payments over time and HealthCoin were the most favorable options.

Although HealthCoin became a popular option, most respondents indicated that legislative change (which would be required to implement HealthCoin) is the most significant barrier to the implementation of any policy.

Thy $\mathrm{n}$ the past decade, expenditures for specialty pharmaceuticals in commercially insured plans have been growing by over $18 \%$ per year. ${ }^{1}$ While these drugs represent less than $1 \%$ of prescriptions written, they now account for $38 \%$ of overall drug expenditures. This trend was highlighted in 2014 , as spending for specialty drugs grew by over $30 \%$, in large part because of increased spending on the newer hepatitis $\mathrm{C}$ therapies. Specialty drugs such as these are a novel class of high-priced medications with the potential to cure diseases. Despite the obvious benefits, health care decision makers are just beginning to grapple with questions of how to value and pay for curative therapies that may have the unique feature of a large upfront cost, followed by health benefits that are reaped over a patient's lifespan. Public and private health systems more commonly deal with treatments for chronic conditions or low-cost vaccines-not one-time cures in which the costs are upfront-that require long-term patient enrollment for the 
plans to reap the financial benefits. Adding to these problems is that new treatments for high value, high prevalence disease can have large budgetary effects in the short to intermediate term.

Traditional utilization management tools may not be sufficient to ensure high value and affordable use of these treatments. Utilization management tools can be thought of as a set of methods that attempt to ensure that only those patients with the highest potential to benefit receive treatment, while limiting the cost exposure of less restrictive policies. But in cases of cures that are high value for a large population and in which the value is realized over patient lifetimes, current utilization management practices would not achieve the greatest societal value. In this context, alternative policies have been proposed to address affordability and value..$^{2-18}$

For any policy to be accepted in the United States, there needs to be engagement from health care insurers and biomedical manufacturer stakeholders. Therefore, gauging the acceptability of the policy options to these stakeholders is important. In order to assess the acceptability of alternative policies, managed care stakeholders would need to be educated regarding the options.

The Academy of Managed Care Pharmacy (AMCP) continuing pharmacy education ( $\mathrm{CPE}$ ) sessions provided a suitable platform to educate stakeholders regarding alternative options and to survey them regarding the acceptability of the options. The annual meeting is AMCP's major educational meeting of the year and draws more than 3,000 attendees. Attendees include managed care pharmacists, health plan administrators and medical directors, formulary decision makers, Medicare Part D and Medicaid administrators, and biomedical manufacturers. CPE sessions are accredited by the Accreditation Council for Pharmacy Education.

The objectives of this study were to (a) briefly review pharmaceutical policy options to address health system affordability and (b) assess the acceptability of alternative policy options to health care payers and biomedical manufacturers.

\section{Methods}

\section{Literature Review}

We conducted a review of the peer-reviewed and grey literature using MEDLINE and Cochran databases to identify articles describing policy options for addressing affordability in pharmaceuticals from June 2000 to July 2016. We identified 21 policy options and categorized the options according to their direct effects on demand, supply, price, or budget (Table 1).

\section{Survey Development, Participants, and Administration}

We conducted a 75-minute CPE session and administered an audience response survey before and after the session at the 2016 AMCP Annual Meeting. The session was entitled "Paying for Cures: How Can We Afford It?" and was held on April 20, 2016.
In order to identify the most promising managed care pharmacy policies to be presented at the AMCP CPE session, we convened a focus group on March 16, 2016, and presented the list of 21 policy options identified from the literature to a group of 8 managed care pharmacists and 4 pharmacy technicians recruited through purposive sampling from a large notfor-profit health plan in Washington State. We identified the top 9 policies to be presented at the CPE session and the top 3 policies to be discussed in detail during the session. Each of the top 3 options were presented in the same structured format (definition, hypothetical example, and limitations) and allotted the same amount of time for presentation.

We then developed an 8-question survey with 3 major parts: (1) characteristics of survey participants (2 questions); (2) pre- and posteducation assessment of the need for and acceptability of alternative policy options to address affordability (5 questions); and (3) major barriers to adoption of alternative policies (1 question). Table 2 lists the 6 questions that assessed the alternative policies.

We assessed the content validity of the survey by administering the survey to the focus group and included 10 additional individuals representing biomedical manufacturers involved in pricing decisions. The final survey was based on the feedback from this larger group.

All attendees of the CPE session were invited by the speaker (Dr. Yeung) to participate in the survey. Responses were captured using Poll Everywhere, a cloud-based audience response system. ${ }^{19}$ This research was approved by the Institutional Review Board at the University of Washington.

\section{Data Analysis}

We first conducted a chi-squared goodness of fit to assess whether responses differed from random distributions. Next, we tested whether the CPE session changed responses for 2-question pairs. We used an ordered logit model clustering by respondent to model the 5 -point Likert scale responses for questions 4 and 6 . We used a multinomial logit model clustering by respondent to model the 8 possible policy responses for questions 5 and 7. All analyses were done with Stata, version 13.1 (StataCorp, College Station, TX). Estimates with $P$ values less than 0.05 were considered statistically significant.

\section{Sensitivity Analyses}

We tested whether the responses to survey questions depended on the respondent's employment (academia, government, managed care, manufacturer, or other) and whether the respondent dealt directly with coverage determination or pricing. We used ordered logit model for Likert responses (questions 3, 4, and 6) and multinomial logit for unordered responses (questions 5, 7, and 8). 


\section{TABLE 1 Policy Options for Addressing Affordability of Prescription Drugs}

Modify supply

- Speed approval or reduce investment costs

- FDA reform ${ }^{4}$

- Make research and development more predictable ${ }^{4}$

- Increase competition

- Accelerate approval of competitors 3,4

- Modify monopoly rules

- Patent buyout ${ }^{3}$

- Modify patent duration ${ }^{27}$

\section{Modify demand}

- Payment reform ${ }^{4,6}$

- ACOs or shared savings and risk contracts with providers

- Episode-based treatment

- Patient-centered medical home

- Consumer/provider price transparency ${ }^{4,28}$

- Consumer/provider value transparency (e.g., require cost-effectiveness information at launch) ${ }^{3}$

- Update value and outcomes information via registries ${ }^{3}$

- Educational measures

- Towards providers: academic detailing29,30

- Towards patients: mass media interventions (radio, television, newspapers, posters, and leaflets) ${ }^{31}$

- Utilization management ${ }^{\top}$

- Prior authorization

- Formulary

- Step therapy

- Specialist prescribing

- Quantity limits

- Budget: financial ceilings on health care expenditures (e.g., United Kingdom, Denmark, Italy) ${ }^{7}$

- Global

- General practitioner level (e.g., Germany and United Kingdom)

- Incorporate cost into clinical guidelines 32

Directly modify price

- Reference pricing 5,7

- Reference other countries 5

- Reference a bioequivalent (i.e., generic) $\operatorname{drug}^{8}$

- Reference a therapeutically equivalent drug8

- Set profit ceilings ${ }^{7}$

- Allow CMS to negotiate or regulate prices ${ }^{5}$

Increase budget

- Toward patients

- Government-established funds for expensive drug purchases. Patient borrows from the funds to pay for out-of-pocket costs, and the loan is amortized over a repayment period as with other consumer loans, such as mortgages, credit card debt, and auto and student loans ${ }^{9}$

- Securitization or government guarantees to reduce interest rates for loans ${ }^{10}$

- Toward payers

- Federal government could guarantee or subsidize health care loans to payers to achieve lower interest rates

- Payments over time 11,12

- Risk-sharing payments over time ${ }^{13,14}$

- Reinsurance of payers ${ }^{11,12}$

Reward value

- Incentivize research and development for cost-effective treatments ${ }^{3}$

- Indication-based pricing $4,17,18$

- Performance-based risk sharing5,14

- HealthCoin 20,21

- Incorporate value into evaluations and negotiations $5^{5,15,16}$

$A C O=$ accountable care organization; $C M S=$ Centers for Medicare $\&$ Medicaid Services; FDA = U.S. Food and Drug Administration. 
TABLE 2 Perceptions Regarding the Sufficiency of Current Managed Care Tools, Alternative Policy Options, and Barriers to Implementation of Alternative Options

\begin{tabular}{|c|c|c|}
\hline Response Options & $\begin{array}{l}\text { Number of } \\
\text { Respondents }\end{array}$ & $\begin{array}{l}\text { Percentage of } \\
\text { Respondents }\end{array}$ \\
\hline \multicolumn{3}{|l|}{ Before Education on Policy Options } \\
\hline \multicolumn{3}{|c|}{ Question 1: Current managed care tools are sufficient to manage the affordability of high-cost curative treatments. } \\
\hline Strongly disagree & 46 & 32.39 \\
\hline Disagree & 65 & 45.77 \\
\hline Neither agree or disagree & 19 & 13.38 \\
\hline Agree & 6 & 4.23 \\
\hline Strongly agree & 6 & 4.23 \\
\hline \multicolumn{3}{|c|}{ Question 2: In the foreseeable future, you will consider alternative financing options to manage high-cost curative treatments. } \\
\hline Strongly disagree & 6 & 4.11 \\
\hline Disagree & 8 & 5.48 \\
\hline Neither agree or disagree & 42 & 28.77 \\
\hline Agree & 62 & 42.47 \\
\hline Strongly agree & 28 & 19.18 \\
\hline \multicolumn{3}{|c|}{$\begin{array}{l}\text { Question 3: In the future, if there are situations in which traditional managed care tools are insufficient for addressing payer affordability, } \\
\text { which of the following is the most promising alternative policy? }\end{array}$} \\
\hline Encourage competition & 17 & 13.49 \\
\hline Direct price control & 27 & 21.43 \\
\hline Indication-based pricing & 18 & 14.29 \\
\hline Payments over time & 7 & 5.56 \\
\hline Risk-sharing payments over time & 47 & 37.30 \\
\hline HealthCoin & 5 & 3.97 \\
\hline Other & 3 & 2.38 \\
\hline None & 2 & 1.59 \\
\hline \multicolumn{3}{|c|}{ After Education on Policy Options } \\
\hline \multicolumn{3}{|c|}{ Question 4: In the foreseeable future, you will consider alternative financing options to manage high-cost curative treatments. } \\
\hline Strongly disagree & 5 & 4.46 \\
\hline Disagree & 7 & 6.25 \\
\hline Neither agree or disagree & 19 & 16.96 \\
\hline Agree & 52 & 46.43 \\
\hline Strongly agree & 29 & 25.89 \\
\hline \multicolumn{3}{|c|}{$\begin{array}{l}\text { Question 5: In the future, if there are situations in which traditional managed care tools are insufficient for addressing payer affordability, } \\
\text { which of the following is the most promising alternative policy? }\end{array}$} \\
\hline Encourage competition & 6 & 5.00 \\
\hline Direct price control & 16 & 13.33 \\
\hline Indication-based pricing & 9 & 7.50 \\
\hline Payments over time & 1 & 0.83 \\
\hline Risk-sharing payments over time & 42 & 35.00 \\
\hline HealthCoin & 39 & 32.50 \\
\hline Other & 6 & 5.00 \\
\hline None & 1 & 0.83 \\
\hline \multicolumn{3}{|c|}{ Question 6: In evaluating an alternative policy, which of the following may be the most important factor limiting adoption of the policy? } \\
\hline Requires legislative change & 61 & 53.51 \\
\hline Does not address enrollee churn & 19 & 16.67 \\
\hline Has high administrative burden & 15 & 13.16 \\
\hline Requires availability of data & 13 & 11.40 \\
\hline Other & 6 & 5.26 \\
\hline
\end{tabular}

\section{Results}

\section{Policy Options}

The policy options that were identified from the literature differed in relation to how they affected affordability and at which level of organization they could be implemented (Table 1).
Different options could be implemented at the federal, state, or health care organization levels. ${ }^{2}$ Some options attempt to increase competition by speeding drug approval or reducing patent duration. ${ }^{3-5}$ Others attempt to modify demand by making the prices of drugs more transparent to patients or 
providers, incentivizing patients or providers to choose lowerprice or higher-value drugs, influencing price directly by using reference pricing, or by allowing direct national price negotiation or control. ${ }^{4-8}$ Still others options recommend increasing budgets by spreading payments over time through health care loans for payers or patients or reinsurance of payers. ${ }^{9-14}$ Finally, some options do not directly address affordability but attempt to reward and pay for value, such as performance-based risk sharing and indication-based pricing, or incorporate value considerations into evaluations and negotiations. ${ }^{3-5,14-18}$

\section{Top 3 Policy Options}

The top 3 policy options that the focus group identified as being least knowledgeable about and that were discussed in detail in the CPE session were payments over time, risk-sharing payments over time, and HealthCoin. ${ }^{20,21}$

Payments over Time. Payments over time can be considered a loan to the health plan from a lender (which can be a drug company or third party) in which payments would be made over time for upfront financing of the treatment. ${ }^{11,14}$ Mattke and Hoch (2015) show that such an arrangement can result in plan savings over time when the ongoing cost of care resulting from not curing an entire population upfront outweighs the ongoing interest payments for the health care loan. ${ }^{14}$ There are 2 limitations to this approach. First, enrollment churn is an issue, since the health plan is investing upfront in the cure for its entire enrollee population and is responsible for the loan payments even if enrollees switch into a competitor's health plan. In this case, the first health plan will be acquiring the loan to finance coverage of the cure for the entire enrollee population but will not reap all the longer-term cost savings. Second, this approach does not address uncertainty regarding the actual effectiveness of the cure. Given that drug approval trials are likely much shorter in duration than a cured individual's remaining lifetime, there is uncertainty regarding the long-term health and economic outcomes of the individual.

Risk-Sharing Payments over Time. Risk-sharing payments over time addresses uncertainty by adjusting the payments over time according to observed effectiveness or cost-effectiveness. ${ }^{13}$ For example, a health plan may contract with a manufacturer to pay $\$ 200,000$ per person-year of cured life. The agreed upon metric would be measured in the enrollee population, and if the observed effectiveness is below the agreed level, payments to the manufacturer would be lowered. Edlin et al. (2014) show that such a strategy can reduce the amount of time to positive returns on investment when applying this strategy to coverage of trastuzumab for the treatment of early breast cancer in the United Kingdom. ${ }^{13}$ One limitation of this approach is that it still does not address enrollee churn. The need to prospectively measure outcomes introduces further limitations of administrative burden and availability of data.
HealthCoin. HealthCoin is a potential tradable currency that would be backed by Medicare, wherein Medicare guarantees payment to the private payer for each treated person entering the Medicare program. ${ }^{20}$ This option incentivizes private payers to invest in upfront coverage for cures, since cured individuals would likely have lower morbidity, and the private payer can sell the remaining value of the HealthCoins when the member switches plans. Basu et al. (2016) present a hypothetical example of a cure for diabetes and demonstrate that a HealthCoin arrangement can lead to higher value for all stakeholdersprivate payers, patients, Medicare, and the manufacturer. ${ }^{21}$ Under a HealthCoin arrangement, the private payer pays for the cure and obtains a net gain of $\$ 10$ billion dollars. Medicare pays for the HealthCoins for those who enroll in Medicare and realizes a net monetary benefit of $\$ 46$ billion. The manufacturer also sells 800,000 more cures. This option has 2 limitations. First, to be implemented, there would need to be legislative action. Second, there would be substantial administrative and data burden in order to track treated individuals and determine the present value of the HealthCoins.

\section{Characteristics of Survey Participants}

Of the 540 session attendees, there were 182 unique survey participants, for a $33.7 \%$ response rate. For the participants, the percentage of questions completed was $68 \%$. Participants were composed of individuals whose employers were managed care $(28 \%)$, government $(4 \%)$, manufacturer $(35 \%)$, academia (5\%), or other $(27 \%)$. Thirty-five percent of the respondents indicated that they dealt directly with coverage determination or pricing of health care interventions. The responses to all survey questions differed statistically from random distributions $(P<0.001)$

\section{The Sufficiency of Current Managed Care Tools and the Acceptability of Policy Options}

The majority (78\%) of participants felt that the current managed care tools were insufficient to manage the affordability of high-cost curative treatments (Table 2). Before the education session, $62 \%$ of the respondents felt that they would consider alternative financing options to manage high-cost curative treatments. After the session, this percentage increased to $72 \%$. Overall, the education session was associated with 1.47 times the odds of considering alternative financing options, but this effect was not statistically significant $(P=0.057)$. Whether respondents directly dealt with coverage or pricing determination was not statistically significantly associated with responses to any question $(P=0.120)$.

Alternative Policy Options and Potential Barriers to Adoption Before the education session, the top 3 options that respondents felt to be the most promising alternative policies were risk-sharing payments over time (37\%), direct price control 
(21\%), and indication-based pricing (14\%). After the session, the top 3 options were risk-sharing payments over time (35\%), HealthCoin (33\%), and direct price control (13\%). This change in response is statistically significant $(P<0.001)$ and appears to be driven by an increase in the number of respondents choosing HealthCoin as the most promising policy option. The CPE session increased the likelihood of individuals choosing HealthCoin compared with choosing none of the options as promising by 15.6 times $(P=0.001)$. The majority $(54 \%)$ of respondents felt that the requirement for legislative change was the greatest limiting factor for the adoption of an alternative policy.

\section{Discussion}

$\overline{\text { Increases in prescription drug expenditures in the past decade }}$ have prompted health plans to rely heavily on traditional utilization management tools. Yet, we found that participants felt that the current managed care tools were insufficient to manage the affordability of high-cost curative treatments and were open towards considering alternative policy options. The survey showed that respondent views regarding the favorability of options were different before and after the CPE session. While risk-sharing payments over time remained the most favorable choice before (37\%) and after (35\%) the education session, this option was closely followed by HealthCoin after the education session, which increased in favorability from 4\% to 33\%. Interestingly, although HealthCoin became a popular option, most respondents indicated that legislative change (which would be required to implement HealthCoin) is the most significant barrier to the implementation of any policy. Clearly, much additional consideration would be required before the implementation of such a policy.

The findings from the survey used in this study are in line with the concerns raised by other payers regarding the affordability of curative drugs and the need for alternative policy options. ${ }^{5}$ In a letter to the U.S. Congress, the National Association of Medicaid Directors point out that prior authorization, Medicaid's primary utilization management tool, is "limited and should not be seen as a long-term solution." The association also raised the issue of high upfront costs, enrollment churn, and uncertainty regarding long-term benefit, particularly in unstudied subgroups. This study shows that stakeholders require a source of information on alternative policy options presented from a balanced perspective.

\section{Limitations}

This study has some limitations to consider. First, the survey was based on the sample of individuals who attended the $\mathrm{CPE}$ session, limiting generalizability. However, the AMCP Annual Meeting is the nation's largest gathering of managed care stakeholders. ${ }^{22}$ Second, the response rate was $33.7 \%$. Respondents are likely to be different from nonrespondents in terms of experience and opinions. However, our response rate was higher than or equal to the response rate in other surveys of managed care stakeholders and biomedical manufacturers (7.7\%-34.7\%). ${ }^{23-26}$ Third, because of constraints on the duration of the CPE presentation, we limited the policy choices to 8 and discussed in detail only 3 of the those. Future research should consider a survey of the full list of options.

\section{Conclusions}

As high-cost curative drugs reach the market, managed care stakeholders need information regarding alternative policies to address affordability and value from a balanced educational source. We found that after the CPE session, risk-sharing payments over time and HealthCoin were the most favorable options. Policymakers should weigh the acceptability of these options against the financial and administrative barriers that need to be overcome.

\section{Authors}

KAI YEUNG, PharmD, PhD, Kaiser Permanente Washington Health Research Institute, Seattle, and Pharmaceutical Outcomes Research and Policy Program, University of Washington, Seattle. KANGHO SUH, PharmD, MS; LOUIS P. GARRISON, PhD; AASTHAA BANSAL, PhD; and JOSH J. CARLSON, PhD, MPH, Pharmaceutical Outcomes Research and Policy Program, University of Washington, Seattle. ANIRBAN BASU, PhD, Department of Health Services, School of Public Health, and Pharmaceutical Outcomes Research and Policy Program, University of Washington, Seattle.

AUTHOR CORRESPONDENCE: Kai Yeung, PharmD, PhD, Kaiser Permanente Washington Health Research Institute, Metropolitan Park East, 1730 Minor Ave., Ste. 1600, Seattle, WA 98101. Tel.: 206.287.2900; E-mail: yeung.k@ghc.org.

\section{DISCLOSURES}

No funding was provided for this research. Carlson reports consulting fees from Genentech, Pfizer, and Seattle Genetics. The other authors have nothing to disclose.

Study concept and design were contributed by Yeung, Garrison, and Carlson. Yeung collected the data, which were interpreted by Yeung and Basu. The manuscript was written by Yeung, Suh, and Bansal and revised by Yeung.

A portion of this research was presented at the Academy of Managed Care \& Specialty Pharmacy Annual Meeting as a continuing education session entitled "Paying for Cures: How Can We Afford It?" on April 20, 2016, in San Francisco, California.

\section{REFERENCES}

1. Express Scripts Lab. Express Scripts 2015 drug trend report. March 2016. Available at: https://lab.express-scripts.com/lab/ /media/d82d33d9686a4c5aab3labb87ecdc73a.ashx. Accessed August 17, 2017.

2. Kesselheim AS, Avorn J, Sarpatwari A. The high cost of prescription drugs in the United States: origins and prospects for reform. JAMA. 2016;316(8):858-71. 
3. Siddiqui M, Rajkumar SV. The high cost of cancer drugs and what we can do about it. Mayo Clinic Proc. 2012;87(10):935-43.

4. U.S. Department of Health and Human Services. HHS Pharmaceutical Forum: innovation, access, affordability and better health. Webinar. November 20, 2015. Available at: https://www.hhs.gov/hhs-pharmaceuticalforum/index.html. Accessed August 17, 2017.

5. National Association of Medicaid Directors. Letter to Congress to address breakthrough drugs. October 28, 2014. Available at: http://medicaiddirectors.org/wp-content/uploads/2015/08/namd_sovaldi_letter_to_congress_10-28-14.pdf. Accessed August 17, 2017.

6. Cutler DM. Payment reform is about to become a reality. JAMA. 2015;313(16):1606-07.

7. Dukes MNG, Haaijer-Ruskamp FM, de Joncheere CP, Rietveld AH, eds. Drugs and Money: Prices, Affordability and Cost Containment. 7th ed. Amsterdam: IOS Press; 2003.

8. Hoadley J. Adapting tools from other nations to slow U.S. prescription drug spending. National Institute for Health Care Reform. Policy Analysis No. 10. August 2012. Available at: http://nihcr.org/wp-content/ uploads/2016/07/Policy_Analysis_No._10.pdf. Accessed August 17, 2017.

9. Montazerhodjat V, Weinstock DM, Lo AW. Buying cures versus renting health: financing health care with consumer loans. Sci Transl Med. 2016;8(327):327ps326.

10. Philipson TJ, Eschenbach AC. Medical breakthroughs and credit markets. Forbes. July 9, 2014. Available at: http://www.forbes.com/ sites/tomasphilipson/2014/07/09/medical-breakthroughs-and-creditmarkets/\#105d0f861420. Accessed August 17, 2017.

11. Gottlieb S, Carino T. Establishing new payment provisions for the high cost of curing disease. American Enterprise Institute Research. July 2014. Available at: http://www.aei.org/wp-content/uploads/2014/07/establishing-new-payment-provisions-for-the-high-cost-of-curing-disease_154058134931.pdf. Accessed August 17, 2017.

12. Kleinke JD, McGee N. Breaking the bank: three financing models for addressing the drug innovation cost crisis. Am Health Drug Benefits. 2015;8(3):118-26.

13. Edlin R, Hall P, Wallner K, McCabe C. Sharing risk between payer and provider by leasing health technologies: an affordable and effective reimbursement strategy for innovative technologies? Value Health. 2014;17(4):438-44.

14. Mattke S, Hoch E. Borrowing for the cure: debt financing of breakthrough treatments. RAND Corporation. 2015. Available at: https://www.rand.org/ pubs/perspectives/PE141.readonline.html. Accessed August 17, 2017.

15. Lopert R, Elshaug AG. Australia's 'fourth hurdle' drug review comparing costs and benefits holds lessons for the United States. Health Aff (Millwood). 2013;32(4):778-87.

16. Sullivan SD, Yeung K, Vogeler C, et al. Design, implementation, and first-year outcomes of a value-based drug formulary. J Manag Care Spec Pharm. 2015;21(4):269-75. Available at: http://www.jmcp.org/doi/10.18553/ jmcp.2015.21.4.269.
17. Bach PB. Indication-specific pricing for cancer drugs. JAMA. 2014;312(16):1629-30.

18. Miller S. We have to change how we pay for cancer drugs. Express Scripts. June 15, 2015. Available at: http://lab.express-scripts.com/lab/ insights/drug-options/we-have-to-change-how-we-pay-for-cancer-drugs. Accessed August 17, 2017.

19. Poll Everywhere. Text message (SMS) polls and voting, audience response system. Available at: https://www.polleverywhere.com/. Accessed August 17, 2017.

20. Basu A. Financing cures in the United States. Expert Rev Pharmacoecon Outcomes Res. 2015;15(1):1-4.

21. Basu A, Subedi P, Kamal-Bahl S. Financing a Cure for diabetes in a multipayer environment. Value Health. 2016;19(6):861-68.

22. Academy of Managed Care Pharmacy. Who attends AMCP's national meetings? 2016. Available at: http://www.amcpmeetings.org/ past/2016spring/pdf/prospectus.pdf. Accessed August 22, 2017.

23. Tomaszewski D. Biosimilar naming conventions: pharmacist perceptions and impact on confidence in dispensing biologics. J Manag Care Spec Pharm. 2016;22(8):919-26. Available at: http://www.jmcp.org/doi/full/10.18553/ jmcp. 2016.22.8.919.

24. Choi Y, Navarro RP. Assessment of the level of satisfaction and unmet data needs for specialty drug formulary decisions in the United States. J Manag Care Spec Pharm. 2016;22(4):368-75. Available at: http://www.jmcp. org/doi/full/10.18553/jmcp.2016.22.4.368.

25. Nichol MB, Knight TK, Epstein J, Honda DH, Tretiak R. Opinions regarding the Academy of Managed Care Pharmacy dossier submission guidelines: results of a small survey of managed care organizations and pharmaceutical manufacturers. J Manag Care Pharm. 2007;13(4):360-71. Available at: http://www.jmcp.org/doi/abs/10.18553/jmcp.2007.13.4.360.

26. Wu WK, Sause RB, Zacker C. Use of health-related quality of life information in managed care formulary decision-making. Res Social Adm Pharm. 2005;1(4):579-98.

27. Office of the United States Trade Representative. Trans-Pacific Partnership. 2017. Available at: https://ustr.gov/tpp. Accessed August 17, 2017.

28. Henrikson NB, Shankaran V. Improving price transparency in cancer care. J Oncol Pract. 2016;12(1):44-47.

29. Yokoyama K, Doan QD, Godley PJ, et al. Effect of physician profiles and academic detailing on cost and utilization of selective serotonin reuptake inhibitors. J Manag Care Pharm. 2002;8(1):23-30. Available at: http://www. jmcp.org/doi/abs/10.18553/jmcp.2002.8.1.23.

30. Soumerai SB, Avorn J. Principles of educational outreach ('academic detailing') to improve clinical decision making. JAMA. 1990;263(4):549-56.

31. Grilli R, Ramsay C, Minozzi S. Mass media interventions: effects on health services utilisation. Cochrane Database Syst Rev. 2002(1):CD000389.

32. Neumann PJ, Cohen JT. Measuring the value of prescription drugs. N Engl J Med. 2015;373(27):2595-97. 